\title{
Review of Socio-Economic and Psychological Aspects of Lockdown during COVID-19 Pandemic
}

\author{
Yash Kumbhare \\ Medical Intern, Jawaharlal Nehru Medical College, Datta Meghe \\ Institute of Medical Sciences, Sawangi (M), Wardha \\ Corresponding author email: yashkumbhare124@gmail.com
}

\begin{abstract}
The COVID-19 wasdeclared as pandemic on March 112020 by WHO., which proved to be the most pervasive and deadliest pandemic of 21st century. The flu-like illness resulted in millions of deaths. Coronavirus is a respiratory virus, which means that it infects a host through the pulmonary pathway. Droplet expulsions from an infected patient (cough, sneeze, spit) releases the virus into the air and the surrounding non-infected person can breathe in the virus particle, continuing the infection chain. Contact between individuals had to be minimized completely to stop the virus from spreading from one person to another. So, as an effective measure of "breaking-the-chain", several of the countries issued partial and complete lockdown. Along with stringent local/international travel restrictions, frequent use of sanitizers, washing hands, wearing personal-protective-equipment (PPE), are being advised to the personnel working in this situation, especially the forces of law, medical staff, and persons associated with essential services. The pandemic has caused major disruption and devastation to the lives, expectations and livelihoods of people all over the world. This article attempts to explore the various effects of the COVID-19 lockdown on different sectors such as manufacturing, economy, education, social life, mental health, etc.
\end{abstract}

KEY WORDS: CORONAVIRUS, PANDEMIC, IMPACT, LOCKDOWN, SOCIAL DISTANCING, QUARANTINE

\section{INTRODUCTION}

The world today is in lockdown and human beings are maintaining distance from each other. The economies and the lives of everyone are passing through a vicious turmoil. In some countries, some services are being opened with stringent guidelines and rules in place. First we will explain the sequence of events and the reason why a worldwide lockdown had to be implemented.

The Coronavirus: The coronavirus itself is not a new viral progeny, as it has been observed in mild flu cases before. However, the novel coronavirus, more appropriately

Biosc Biotech Res Comm P-ISSN: 0974-6455 E-ISSN: 2321-4007

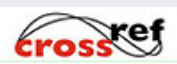

Identifiers and Pagination

Year: 2021 Vol: 14 No (6) Special Issue

Pages: 303-309

This is an open access article under Creative

Commons License Attribn 4.0 Intl (CC-BY).

DOI: http://dx.doi.org/10.21786/bbrc/14.6.64 called SARS-CoV-2, has some mutation in its structure that gives it an unprecedented infective rate. The virus, like its normal counterpoint, contain spike proteins that help in its attachment to the host cell. A report suggests that the mutated spike protein of the SARS-CoV-2 can be activated by Furin, a ubiquitous enzyme of the host. The Furin activation gives the virus the capability to infect a lot of host cells. The Coronaviridaeare known to prefer the oropharyngeal and nasal route, giving rise to high fever, trouble in breathing, cough, and other symptoms of flu. Several other viral glycoproteins or lipopolysaccharide contribute to the infectivity and pathogenesis of novel SARS-CoV-2.

The Event Timeline: The preliminary reports of this virus came from the seafood and fish markets of Wuhan province, China, during November-December 2019, which gave it the name COVID-19. According to the reports coming into light now, the authorities in the Wuhan province initially continuously downgraded the threat by stating that human-to-human transmission was impossible. After a case of infection in Vietnam,

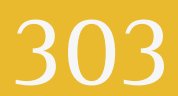


with absolutely no connection to that market was detected, the human-infective nature of COVID-19 was confirmed by the WHO. At that time, the virus had started to spread worldwide, and the death and infected toll increased continuously. Within January 21 2020, the first case of coronavirus was reported in the US. At present, 23,952,804 infected patients and 820,047 deaths are reported worldwide. There are several reports of asymptomatic persons also.

The Infection Chain: Coronavirus is a respiratory virus, which means that it infects a host through the pulmonary pathway. Droplet expulsions from an infected patient (cough, sneeze, spit) releases the virus into the air and the surrounding non-infected person can breathe in the virus particle, continuing the infection chain. Contact between individuals had to be minimized completely to stop the virus from spreading from one person to another. So, as an effective measure of "breaking-the-chain", several of the countries issued partial and complete lockdown. Along with stringent local/international travel restrictions, frequent use of sanitizers, washing hands, wearing personal-protective-equipment (PPE), are being advised to the personnel working in this situation, especially the forces of law, medical staff, and persons associated with essential services. The pandemic has caused major disruption and devastation to the lives, expectations and livelihoods of people all over the world. Now, we shall explore the various effects of the COVID19 lockdown on different sectors such as manufacturing, economy, education, social life, mental health, etc.

Study Design: The following study has been divided into the following sections, where we will discuss in detail the effects that the coronavirus pandemic and lockdown have had on each specific area.

- The effect of the lockdown on the global and individual national economies.

- The effect of the lockdown on the global and individual national education sectors.

- The effect of the lockdown on global mental health and well-being.

- The effect of the lockdown on global domestic violence and abuse.

- The effect of the lockdown on the environment.

- The effect of the lockdown on everyday life.

Impact of the Coronavirus Lockdown on the Economy: According to predictions made by the International Monetary Fund (IMF), the global economy is expected to shrink by $3 \%$. This is the single biggest economic recession since the Great Depression of the 1930s (Jones $\mathrm{L}$, et al 2020). To control the spread of the virus and to "flatten the curve" of the infection, most governments across the world implemented strict social distancing protocols and lockdowns. These lockdowns resulted in people being forced to stay inside their homes. As a result, economic activity all over the world was affected severely and millions of business owners were forced to close up shop. To understand precisely how the Coronavirus pandemic and the lockdown has affected the global economy, we have to look at the biggest trading countries one-by-one.

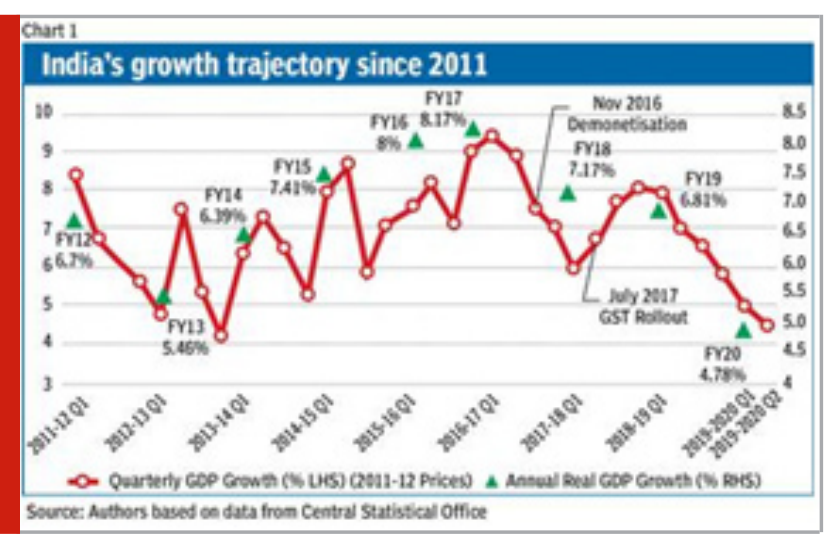

The United States of America has been one of the countries worst-hit by the Coronavirus outbreak. Due to shoddy and careless safety measures being taken by the US administration and the overall callousness of the government, the economy of the US has also been affected greatly. There have been many major disruptions to normal economic activity and millions of people have suddenly found themselves without a job. The labour market of the US has been affected very badly, and a Reuters report found out that more than 36 million Americans applied directly to the federal government for unemployment benefits. This number is over $25 \%$ of the existing American workforce. The manufacturing output has fallen in all major industrialized nations, which has caused a fall in external and domestic demand.

Something that must be noted is that the economies of industrialized and developed nations are projected to suffer more than the economies of less-developed nations. The IMF reports that the advanced economies of the world are projected to contract by $6 \%$. On the other hand, developing countries that are emerging markets are projected to contract only by $2.20 \%$. One of the worst affected countries in this pool is China, whose national income contracted by $36.6 \%$ in the first quarter of the year (CMIE, 2020). Other manufacturing nations like India, South Korea, Japan, etc. are also experiencing contractions in their domestic and external demand. However, the worst-hit economies in the world surely belong to the developing nations of Brazil and India.

India's economic activities have been largely disrupted and devastated by the pandemic and the ensuing lockdown. According to reports filed by the Indian Ministry of Statistics, India's total growth fell down 3 percentage points for the 2020 fiscal year (Goyal M, ET Bureau, 2020). Interestingly, the World Bank had predicted that India would have a low growth rate for the 2021 fiscal year. After the pandemic was announced in March, the rating agencies revised their ratings and India's growth rate slumped even lower. The State Bank of India (SBI) has gone one to say that there is going to be a $40 \%$ contraction in the Indian GDP over the first quarter of the 2021 fiscal year. 
When the lockdown was announced, unemployment levels rose from $6.7 \%$ to $26 \%$. In mid-June, the numbers returned to their pre-lockdown position. The migrant labourers and day-workers of India have been one of the worst affected. The lockdown was suddenly announced by the Indian Government without any prior warning, and millions of labourers found themselves without work or shelter. Many were forced to return home by foot, and newspapers and social media was plastered with images of labourers walking along the highway. The situation was improved slightly after Indian Finance Minister, announced a 24 billion USD spending plan for the poor. The lockdown also caused a major disruption in the supply chain of the country's economy, with major players like Amazon, Flipkart, Big Basket, etc. suspending operations during the first phase of the lockdown.

On March 23 2020, the Indian stock market also took a major dive. According to reports, the BSE SENSEX fell more than 4000 points while the NSE NIFTY fell more than 1150 points. Commentators announced that these were the worst losses in India's history. However, this situation did not spiral out of control as the SENSEX and NIFTY both posted their biggest profits in 11 years just 2 days later. After the lockdown was announced, more than 66 billion USD was channelled towards the Indian investors. To tackle the steadily declining situation for the country, India's central bank and government rolled out a number of stimulus and support packages. Initially, the RBI said that it would provide 52 billion USD to the struggling Indian economy along with 7 billion USD worth of financial assistance to NABARD, NHB and SIDBI. On May 12, Indian Prime Minister announced an "overall" economic package worth 280 billion USD. After these measures, economic analysts have said that the national economy is recovering faster than expected. However, the coronavirus lockdown has surely left its mark on the global and national economies.

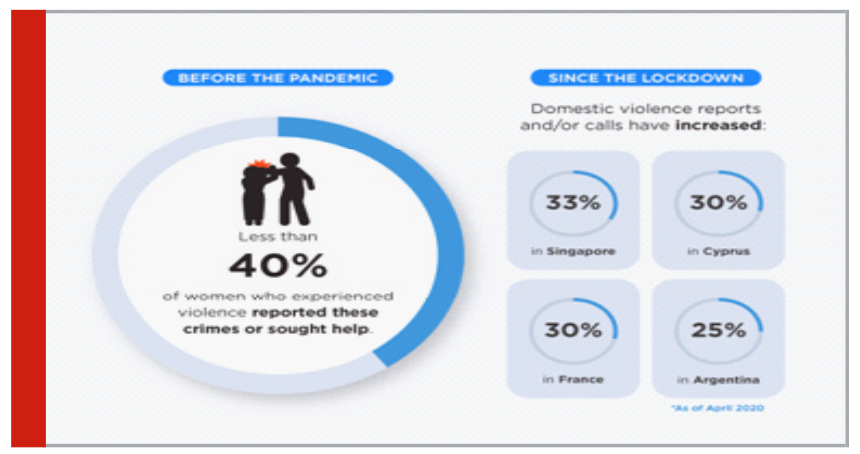

Impact of the Coronavirus Lockdown on the Education Sector: The COVID-19 pandemic and the ensuing lockdown has caused major disruption in the educational and skills training system all over the world. Schools, colleges, universities, etc. have been forced to suspend classes indefinitely until the situation improves. Most major educational institutions and private schoolshave started to switch to online modes of education. Their educators and teachers have also started to conduct classes with the help of online communication and video chatting suites like Discord, Zoom, Google Meet, Google
Classroom, etc. However, the situation is extremely bad in less developed countries, where students do not have access to smartphones, computers, high-speed internet, etc. According to a study conducted by UN Women, more than $89 \%$ of the global school student population is currently out of school due to the coronavirus pandemic and lockdown (UNESCO 2020).

The main reason behind the suspension of classes was an attempt to flatten the infection curve. Mathematical models and research have predicted that closing down schools and universities would restrict transmission of the virus from one person to another. For this measure to be properly effective, students also need to practice social distancing and obey all the guidelines issued by local governments and the WHO. In the late stages of the pandemic, the situation of the educational sector continues to look bleak. According to monitoring and reports by the UNICEF, more than 1.725 billion learners are currently affected due to the coronavirus pandemic. In many countries, board examinations and college admissions had to be postponed indefinitely because of the lockdown.

For example, the Indian CBSE and ISC qualifying examinations were initially postponed and then cancelled altogether. In the United Kingdom, there have also been protests and outrage after the A-Level examinations were marked by means of an algorithm - which led to students studying in poorer schools receiving lower marks than students studying in richer schools.

Many educators and legislators have started to realize that distance and online learning is not always a viable method. Especially in developing nations, a huge section of the population does not have access to highspeed internet and technology. This sort of asymmetric access to resources can already widen the gap that exists between the upper and lower classes. For this exact reason, educators and activists all over the world have been campaigning for free and unfettered access to educational resources for schoolchildren, college students, educators, etc.

Impact of the Coronavirus Lockdown on Mental Health The coronavirus lockdown has also had an adverse effect on the mental health of global citizens. In the 21st century, it is especially important to realize the important of mental health. Sound mental health is not a boon - in fact, it is a product of situations and access to resources. This is precisely why poor mental health is often equated to declining socioeconomic circumstances, such as poverty, unemployment, poor healthcare, etc. The coronavirus pandemic and the ensuing lockdown has had a devastating effect on the mental health of people all over the world. A recent survey showed that $69 \%$ of the UK population is feeling very stressed and anxious about COVID-19's effect on their lives (Psychiatr.J 2020)

The section of the population that has been hit the worst are young people, who are either pursuing higher education or starting new jobs. As a result of being 
cooped up in their homes, away from loved ones, for a long amount of time, many people are experiencing heightened anxiety and depression. The uncertainty of people's future and concerns about their health has caused people to have a mental health spiral. Additionally, the lockdown has also caused major economic downturns worldwide. As a result of this, many people are also finding themselves out of jobs or options. This has led to the outbreak of various mental health concerns such as depression, anxiety, OCD, bipolar disorder, etc. (Khatun S, 2020).

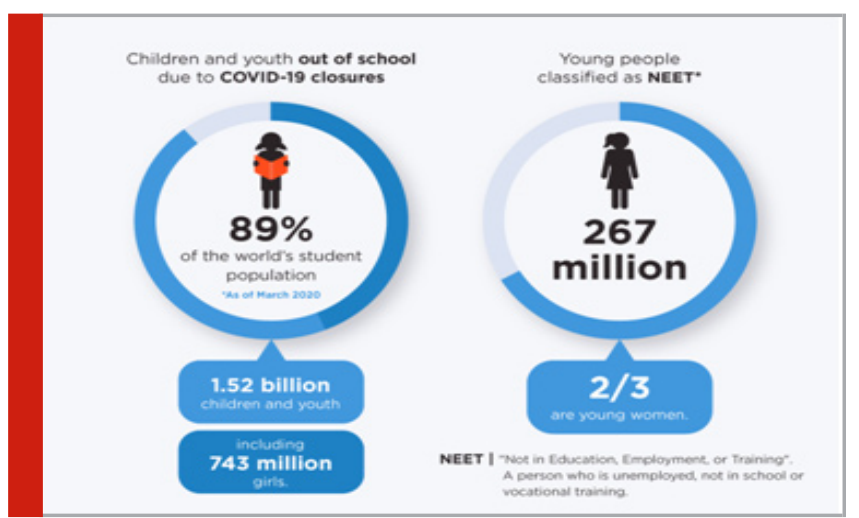

Social distancing protocols also prevent individuals from reaching out to friends and family. Even though they can communicate with their loved ones via the phone and the internet, it is difficult to replace human interaction completely. Also, it is absurd to expect every single person to have continuous access to high-speed internet and technology. Many people are also finding it exceedingly difficult to stay in contact with their therapists and mental health counsellors.

Impact of the Coronavirus Pandemic on Domestic Violence: The COVID-19 pandemic has brought along with it a surge in cases of domestic violence and abuse, as many survivors have been forced to stay at home with abusive parents and partners. The situation has become so frightening that Antonio Guterres, the Secretary-General of the United Nations has addressed the problem and called it a "horrifying global surge (Farran, G. Albert, 2020). Domestic violence is already one of the most pervasive and horrifying problems that the world has to face on a daily basis. The coronavirus pandemic, lockdown and social distancing protocols have exacerbated an already serious issue. Households all over the world are experiencing a lot of financial and health issues, and this has caused a huge spike in the number of domestic violence cases. Women and children are among the most vulnerable at this time.

Before the pandemic was announced, the UN made projections that a third of all women would face violence and abuse during their lifetime. Apart from being a huge human rights issue, this gross miscarriage of justice also carries with it an economic cost of 1.5 trillion USD. Due to the pandemic and the lockdown, many of these vulnerable women are trapped at home with their abusers, and it is virtually impossible for them to escape.
The healthcare system is already overloaded due to the medical attentions demanded by the pandemic and the justice system is also at a virtual standstill. This has put millions of women at risk all over the world. Essential and informal workers who happen to be female are also at an increased risk of violence, according to data and projections made by UN Women.

One of the countries worst affected by this pandemic of domestic violence and abuse is India. According to the Indian National Commission for Women (NCW), gender-based violence has almost doubled during the coronavirus lockdown. When the first 21-day lockdown was declared, the NCW registered almost 600 confirmed complaints of domestic violence and abuse. This was a $45 \%$ increase from the 25-day period previous to the lockdown's implementation. Indian society is largely patriarchal and there is an incredible gap between the way Indian society treats and views men and women. Due to financial worries caused by the lockdown, many innocent women and children had to suffer violence and abuse at the hands of their parents and partners. The police have also been showing increased apathy towards complaints of domestic abuse since they are busy with lockdown orders.

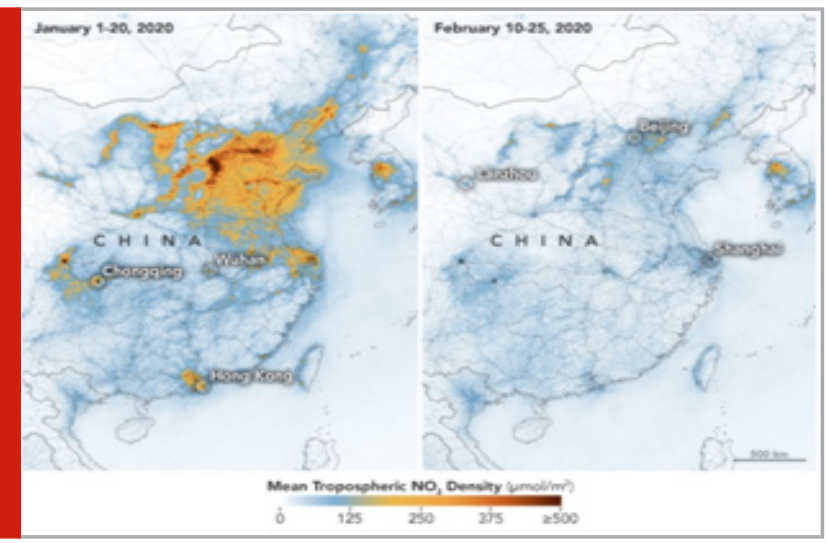

Impact of the COVID-19 Pandemic on the Environment: The COVID-19 pandemic, lockdown and travel restrictions has caused a lot of disruption in industrial activity, planned travel, construction, etc. This has led to a large drop in air pollution and carbon emissions in major manufacturing countries all over the world. In China alone, the coronavirus lockdown caused a $25 \%$ reduction in carbon emissions and a 50\% reduction in nitrous oxide emissions (Zambrano A. Manuel, 2020). Carbon emissions contribute to the greenhouse effects and global warming while nitrous oxide emissions cause lung diseases, asthma and cancer. Since there has also been a disruption in planned travel and flights due to travel restrictions and border closures, transportation emissions have also decreased exponentially.

Aquatic life has made a resurgence in current months due to a fall in demand for seafood and fish prices. Fishing fleets and trawlers are currently lying dormant - mainly because of the drop in demand and lockdown restrictions imposed by local governments. German 
scientists have predicted that commercial fish like the herring are projected to double their biomass by the end of this year. Due to the lowered levels of human interaction and interference, many aquatic species have started to flourish. There has also been a 60\% reduction in the amount of vehicular accidents involving wildlifeall over the United States (Venter S. 2020).

However, many conservationists and legislators are worried that there is going to be a surge in poaching and illegal hunting across forest conservations in Africa and Southern America. Under the cover of the Coronavirus lockdown, many poaching and animal trafficking gangs have started to operate. Many scientists have also predicted an increase in the number of zoonotic diseases as well, due to the consumption of unsterilized game meat. Many governments have also started to pass legislation that will enable them to move towards more renewable and sustainable forms of energy. One of the biggest examples is the European Union (EU), which implemented a $€ 1$ trillion proposal that will reserve $25 \%$ of EU budget allocation towards sustainable and climate-friendly expenditure.

Impact of the COVID-19 Pandemic on the Everyday Life of People: Even though there has been a lot of examination into the way the coronavirus pandemic and lockdown have affected global economies, mental health and educational systems; there has been very little inquiry into the way that the pandemic has affected the everyday life of people. One of the biggest changes is the wearing of a face mask. Governments and public health organizations like the WHO have been advising people to wear masks when they go out. The objective of the mask is to prevent individuals from transmitting the virus while they are outdoors. Apart from preserving their own health and safety, the mask is also designed to protect those with immune issues by utilizing herd immunity.

Even though the mask has become a vital part of everyone's lives, many people have actually taken to the streets to protest mask usage. In the United States, many Senators and local lawmakers have gone on record stating that they will not be wearing a face mask for religious reasons. This has led to a lot of ridicule and criticism on social media, which is especially directed at individuals who refuse to wear masks at retail establishments, public places, etc. Many people have started to comment on the mask as a "violation of freedom" as well. Apart from masks, social distancing protocols have also changed the way people interact with each other. Many people are also avoiding public transport and socialization in an effort to stay safe (Stewart E, 2020).

Lastly, I think it is safe to say that this pandemic has completely changed the way that human beings interact and behave with each other. Until a reliable vaccine is developed, people will have to wear masks, practice social distancing and sanitize themselves as much as they can. Extra measures need to be taken to protect the health and safety of immunocompromised individuals, infants, elderly people, cancer patients, etc. The human race will overcome this tough situation once they start showing a little empathy.

Rules To Stringently Follow During Lockdown: The infection profile of SARS-CoV-2, or more commonly called the COVID-19 virus has spread it worldwide without any functional treatment regimen to date. Vaccines still have clinical trial steps to clear before they can reach the public. According to scientific reports, a mutation in the spike protein in the SARS-CoV-2 surface, along with the interaction with ubiquitous Furin protein of the host, has made this virus readily infectious and capable of adsorption into any tissue.

The Primary Step To Discontinue the Infection Trend: The main dangers associated with the CoVID-19 infection is that it can infect human through droplet inhalation. Simply stated, the expulsed droplets (through sneezing, coughing, or spitting) from an infected person can transmit to the virus to a non-infected person coming into direct or indirect contact through the pulmonary pathway. The virus can live differently on various surfaces, so unprotected contact can also cause infection. To inhibit the spread from the source, the most effective way is to maintain social distancing, at least $6 \mathrm{ft}$. from one another. Inhibition through one person can cause disruption in the infection cycle, thereby stopping the course of contamination.

Other Rules to Strictly Follow: Even in the lockdown situation, some of the services have to be continued as before, like electricity, network connection, food, and other essentials. The rules that the associated official can follow would be given as;

1. Use personal-protective-equipment (PPE) like masks, face shields, gloves, as and when applicable.

2. Use sanitizers as and when you have come in contact with uncovered surfaces.

3. Avoid touch altogether, even for a simple thing such as shaking hands.

4. After coming from outside, sanitize everything; clothes, bags, masks. It is a good practice to sanitize your wallet, pens, and digital devices before entering your home.

5. If any of the disease indication surfaces, go into self-imposed quarantine for 14 days. Act according to the doctor's instruction.

6. The persons who are staying inside the house at this time are less susceptible to coronavirus infection. However, some rules also have to be maintained by them:

1. Periodically sanitize your work surfaces, especially if it has been in contact with someone coming from the outside.

2. Stay inside your home. More you remain out of contact from outside, less is the chance of infection for you and your family members.

3. Maintain the routine you had previously.

4. Determine an optimum screen-time to avoid eye- 
problems.

5. Consume fruits and vegetables more; especially ones that boost immunity.

6. Take part in the assistance of needy following all the guidelines in place.

7. If any of your family members show the symptoms of the disease, impose quarantine guidelines, and follow it strictly.

Staying Safe: The symptoms of SARS-CoV-2 infection that usually necessitates Real-time Quantitative Polymerase Chain Reaction (RT-qPCR) for confirmation are mainly fever, nasal block, fatigue, dry cough, aches and pains, runny nose, sore throat or diarrhoea. Senior citizens, infants, diabetic and hypertensive persons, and persons with reduced immune capabilities are at risk of serious complications. So, extra care will be required in these cases. (Somashekahar et al 2020) reviewed the ASI's Consensus Guidelinesto be followed in Covid 19. (Spoorthy et. al. 2020) have reviewed about mental health problems faced by healthcare workers due to the Covid19 pandemic. Factors related to respiratory health issues in this region are reported in previous studies (Taksande, et al 2016, Dhar, Raja, et al 2019, Salampuria, et al 2019, and Dhar, R., et al 2017). A number of studies reflected on various aspects (Waghmare, A., S. Et al 2020, Wanjari, T.N., and G. Sawarkar 2020, Behere, P.B., et al 2020) and effects (Gaidhane, S., N. et al 2020, Nisargandha, M.A., and S. Dadaraoparwe 2020 and Phansopkar, P., et al 2020) of lockdown in India. Reviews by (Behere et.al. 2020 and Gawai et.al. 2020) addressed the key issues of mental impacts.

\section{REFERENCES}

Barua, S., 2020. Understanding Coronanomics: The economic implications of the coronavirus (COVID-19) pandemic.

Behere, P.B., Behere, A.P. and Chowdhury, D., 2020. Rise in cases of alcohol withdrawal following lockdown in dry district of Wardha. Journal of neurosciences in rural practice, 11(3), p.478.

Behere, P.B., Nagdive, A.B., Behere, A.P., Yadav, R. and Fernandes, R., 2020. Innovation in Community Psychiatry for the Delivery of Mental Health Services: The Sawangi Model. Journal of Neurosciences in Rural Practice, 11(4), p.593..

CMIE, 2020, Seniors save their jobs, 26th August.

Dhar, R., Mohan, M., D’souza, G., Rajagopalan, S., Singh, V., Jindal, A., Ghewade, B., Joshi, G., Sahasrabuddhe, T., Gami, S. and Nair, G., 2017. Phenotype characterization of non cystic fibrosis bronchiectasis in India: baseline data from an Indian bronchiectasis registry. In B 103. CLINICAL STUDIES IN BRONCHIECTASIS, IMMUNODEFICIENCY, AND DRUG INDUCED LUNG DISEASE (pp. A4726-A4726). American Thoracic Society.

Dhar, R., Singh, S., Talwar, D., Mohan, M., Tripathi, S.K., Swarnakar, R., Trivedi, S., Rajagopala, S., D’Souza, G.,
Padmanabhan, A. and Baburao, A., 2019. Bronchiectasis in India: results from the European multicentre bronchiectasis audit and research collaboration (EMBARC) and respiratory research network of India registry. The Lancet Global Health, 7(9), pp.e1269e1279.

Gaidhane, S., Khatib, N., Zahiruddin, Q.S., Gaidhane, A., Kukade, S. and Zodpey, S., 2015. Perceptions of primary care doctors towards Type 2 Diabetes Mellitus and challenges for care at primary care level in India. International Journal of Diabetes in Developing Countries, 35(1), pp.14-18.

Gawai, J.P., Singh, S., Taksande, V.D., Sebastian, T., Kasturkar, P. and Ankar, R.S., 2020. Critical Review on Impact of COVID 19 and Mental Health.

Hiremath, P., Kowshik, C.S., Manjunath, M. and Shettar, M., 2020. COVID 19: impact of lock-down on mental health and tips to overcome. Asian journal of psychiatry, 51, p. 102088.

Latchoumi, T.P., Ezhilarasi, T.P. and Balamurugan, K., 2019. Bio-inspired weighed quantum particle swarm optimization and smooth support vector machine ensembles for identification of abnormalities in medical data. SN Applied Sciences, 1(10), pp.1-10.

Nisargandha, M.A. and DadaraoParwe, S., 2020. Spread of coronavirus disease 2019 (COVID-19) during thelockdownintheIndianpopulationandpreventive measures. International Journal of Research in Pharmaceutical Sciences, 11, pp.328-332.

Phansopkar, P., Naqvi, W.M. and Kumar, K., 2020. Musculoskeletal check in smartphone overuse in COVID 19 Lockdown phase. International Journal of Research in Pharmaceutical Sciences, 11(Special Issue 1).

Rossi, R., Socci, V., Talevi, D., Mensi, S., Niolu, C., Pacitti, F., Di Marco, A., Rossi, A., Siracusano, A. and Di Lorenzo, G., 2020. COVID-19 pandemic and lockdown measures impact on mental health among the general population in Italy. Frontiers in psychiatry, 11, p.790. Salampuria, S., Jajoo, S. and Acharya, S., 2019. Acute respiratory distress syndrome during pregnancy and post-partum-a case series with spectrum of near miss to mortality. Journal of Evolution of Medical and Dental Sciences-JEMDS, 8, pp.3724-26.

Scerri, M. and Grech, V., 2020. To wear or not to wear? Adherence to face mask use during the COVID19 and Spanish influenza pandemics. Early human development.

Somashekhar, S.P., Shivaram, H.V., Abhaham, S.J., Dalvi, A., Kumar, A., Gode, D., Misra, S., Jain, S.K., Prasad, C.R.K. and Pillarisetti, R.R., 2020. ASI's consensus guidelines: $A B C s$ of what to do and what not during the COVID-19 pandemic

Spoorthy, M.S., Pratapa, S.K. and Mahant, S., 2020. 
Mental health problems faced by healthcare workers due to the COVID-19 pandemic-A review. Asian journal of psychiatry, 51, p.102119

Taksande, A.M. and Yeole, M., 2016. Risk factors of Acute Respiratory Infection (ARI) in under-fives in a rural hospital of Central India. Journal of Pediatric and Neonatal Individualized Medicine (JPNIM), 5(1), pp.e050105-e050105

UN News, 2020. UN chief calls for domestic violence 'ceasefire'amid 'horrifying global surge'. Global Perspective Human Stories.

Venter, Z.S., Aunan, K., Chowdhury, S. and Lelieveld, J., 2020. COVID-19 lockdowns cause global air pollution declines. Proceedings of the National Academy of Sciences, 117(32), pp.18984-18990.

Waghmare, A. and Shrivastava, S., 2020. Effect of Covid-19 lockdown in trauma cases of Rural India. Int. J. Res. Pharm. Sci., pp.365-368..

Wanjari, T.N. and Sawarkar, G., 2020. Lockdown lifestyle: Engaging the invisible enemy. International Journal of Research in Pharmaceutical Sciences, 11(Special Issue 1).

Zambrano-Monserrate, M.A., Ruano, M.A. and SanchezAlcalde, L., 2020. Indirect effects of COVID-19 on the environment. Science of the Total Environment, 728, p.138813. 